\title{
Documentos
}

\section{Educação de jovens e adultos na América Latina: políticas de melhoria ou de transformação; reflexões com vistas à VI CONFINTEA}

\author{
Lidia Mercedes Rodriguez \\ Universidade de Buenos Aires, Faculdade de Filosofía e Letras \\ Universidade Nacional de Entre Rios, Faculdade de Ciências da Educação
}

Tradução: Beatriz Cannabrava

\section{Introdução}

Parece existir no continente um importante consenso com relação ao reconhecimento da educação como direito - em oposição à ideia de "serviço". No entanto, subsistem importantes dificuldades para garanti-lo. Na região são 35 milhões de adultos analfabetos e 110 milhões de jovens que não concluem o curso primário. ${ }^{1}$

A próxima CONFINTEA desperta, então, importantes expectativas visando a estabelecer acordos que potencializem o desenvolvimento de políticas públicas e ações territoriais em benefício dos setores mais preteridos, ainda mais se considerarmos o atual cenário político, no qual se abrem possibilidades para uma forte recuperação e atualização da tradição educativa de tipo popular e democrático. Embora não tenha

${ }^{1}$ UNESCO-IUAL-INEA. Conferência Regional da América Latina e do Caribe sobre alfabetização e preparatória para CONFINTEA VI "De la alfabetización al aprendizaje a lo largo de toda la vida: Hacia los desafíos del siglo XXI". Cidade do México, 10-13 set. 2008. desaparecido e tenha perdido hegemonia, ressurge com vocabulário atualizado o discurso centrado na relação custo-benefício que relegou a educação de adultos a um plano secundário, subordinando seu potencial transformador à lógica da competição e do mercado.

Nas agendas e nos diversos documentos nacionais e internacionais são incorporados ou reforçados temas de conteúdo democrático que a educação popular foi incorporando ao longo de seu percurso, como o cuidado com o meio ambiente, a atenção ao multiculturalismo, a educação para a saúde, a cultura da paz e dos direitos humanos, para citar alguns.

No sentido democratizante, cresce o reconhecimento de sujeitos específicos e diversos: mulher, jovens, migrantes, pessoas portadoras de necessidades especiais ou em reclusão.

Tudo isso, unido aos temas da tradição da educação de herança freireana - muitos dos quais perderam força nas políticas públicas na década de 1990 -, tais como a formação em cidadania, a valorização da educação "não-formal” em suas diversas modalidades, a continuidade da educação e a aprendizagem ao longo de toda a vida, a necessidade da articulação de 
políticas, do aumento do financiamento e a articulação com o trabalho.

Entretanto, parece que ainda não se consolidou uma proposta alternativa viável de atenção a grandes massas de população com atraso educativo capaz de ser posta em marcha com força política. Essa dificuldade manifesta-se, por exemplo, na distância assinalada por muitos entre a retórica e as ações. Como diz Rivero (2007, p. 4), corremos o risco de, se não foram adotadas políticas decisivas, aumentar o número de analfabetos.

Os documentos gerais precisam construir sínteses para chegar aos necessários consensos e oferecer panoramas globais da região, superando a complexidade representada por sua extrema heterogeneidade em muitos sentidos - cultural, político, social etc. - não apenas entre países, mas internamente em cada um deles.

Oferecem-nos, assim, material para uma análise na qual se pode pôr sobre a mesa os matizes e as tensões presentes, enriquecendo o diálogo que produz conhecimentos e novidades.

É nesses enunciados mais abrangentes que se põe em evidência a particular capacidade da linguagem de ocultar profundas divergências com os mesmos significantes. Elas manifestam-se, por exemplo, na discussão sobre o nome daquilo de que estamos falando. Aprendizagem e Educação de Adultos (AEA), Educação de Pessoas Jovens e Adultas (EPJA), Educação de Jovens e Adultos (EDJA), Educação de Adultos (EDA); diversidade de nomes que é a expressão da complexidade de um debate que encontra no espaço aberto pela institucionalidade democrática uma oportunidade para deslanchar.

Algumas dessas variedades, tensões ou possibilidades diversas inscritas em enunciados de amplo consenso são as que apresentamos a seguir.

\section{Incluir: integrar ou transformar}

No final dos anos de 1960, em sua Pedagogia do oprimido, Paulo Freire já assinalava: "Como marginalizados, 'seres fora de’, ou 'à margem de’, a solução para eles seria que fossem 'integrados', 'incorporados' à sociedade de onde 'partirão' um dia, renunciando, como trânsfugas, a uma vida feliz” (Freire, 1975, p. 76).

Ser “excluído” não é um “estar fora de”, mas, pelo contrário, é ser parte fundamental de uma sociedade, ocupando um lugar. Politicamente subordinado, culturalmente desierarquizado, expressão da "alteridade" depositária daquilo que impede a definitiva constituição de uma sociedade plena. Os chamados “excluídos” não são apenas força de trabalho barata disponível mas também - e talvez seja sua função mais importante o lugar simbólico no qual a sociedade deposita sua impossibilidade de constituição definitiva. ${ }^{2}$

Por isso, “incluir” é, na realidade, mudar de posição em um conjunto do qual já se tomava parte. É possível realizar tal operação sem transformar essa totalidade? $\mathrm{Ou}$, pelo contrário, esse movimento necessariamente modifica o conjunto? "Incluir" implica colocar em discussão as posições de todos os atores, dos que já estavam “dentro".

É, portanto, um movimento impossível sem transformações sociais, econômicas, culturais profundas, ou seja, sem conflito. O marco democrático oferece espaços para uma resolução não traumática, mas não faz desaparecer a pugna por diversos interesses econômicos, por distintas visões de mundo e projetos.

Educar para a inclusão significa, então, potencializar a formação de sujeitos em uma práxis transformadora. A educação de adultos tem uma longa tradição - talvez para potencializar e atualizar - no interesse de produzir subjetividades, onde o desenvolvimento e a melhora progressiva das condições de vida sejam orientados por um horizonte de justiça. Significa uma proposta que potencializa a consolidação de identidades, individuais e coletivas, superando a perspectiva de um humanitarismo assistencial, que surge às vezes em atualizadas modalidades de ressonâncias progressistas.

A outra opção é oferecer migalhas de certificações ou de conhecimentos, supostas ferramentas para que os

${ }^{2}$ Sobre a impossibilidade de fechamento do social, ver, entre outros: Laclau $(1993,1996)$. 
indivíduos sejam mais capazes de sobreviver e procurar emprego, aceitando a lógica do darwinismo social.

\section{Atender urgências ou enfocar as populações}

Nessa perspectiva, distingue-se também a distância entre a imprescindível atenção às urgências - que são normas mínimas de cuidado diante de situações de emergência - do desenvolvimento de ações destinadas a grupos específicos e, portanto, separados da lógica do conjunto. Não há dúvida de que a atenção prioritária pode resolver temporariamente algumas situações, mas é um risco quando é estabelecida como linha política para reforçar o isolamento de grupos e setores sociais do conjunto do qual formam parte.

O estabelecimento de prioridades políticas para a educação de adultos pode ser feito de acordo com as lógicas de um processo de desenvolvimento, de uma aposta política para o futuro. Ou de acordo com uma conta, um cálculo mais parecido com a administração do que com a gestão de política pública. São opções que conduzem a decisões diferentes. Educação como custo ou investimento é um debate que parece que voltou a ser proposto, embora em novos termos.

\section{Respeitar a diferença ou potencializar o desenvolvimento da multiplicidade}

O reconhecimento da diversidade cultural certamente foi um progresso diante da obra colonial da modernidade, na qual o discurso da supremacia étnica, cultural, linguística etc. justificou diversos tipos de genocídio.

Mas esse "respeito" também pode se referir a uma “tolerância”, a “algo fora do comum”, não “normal”, desconhecido e, sem dúvida, gerador de medos mais ou menos inconscientes (Todorov, 2008).

Qual é a lógica pela qual se une multiculturalismo a necessidades educativas especiais ou população em contextos de privação de liberdade, terceira idade ou adultos mais velhos?

É o lugar do que é “diferente”, apontado a partir de um lugar que pensa a si mesmo como centro "não cultural”, branco, sem necessidades especiais, jovem ou maduro, mas não "velho”, geralmente no masculino, e situa aquilo em que não pode reconhecer-se em uma situação periférica. Um gesto que tende a acalmar, "museulogizar”, manter estáticas as múltiplas formas culturais.

Mas também pode se tratar de um impulso para a criação de políticas ativas a favor da preservação e da potenciação dessa multiplicidade que é a riqueza do conjunto. Os grupos humanos querem poder transformar-se em seus próprios ritmos e no marco de não-violência de cosmovisões profundas que são patrimônio da humanidade. Para isso, é imprescindível a superação das posições de subalternidade política ou econômica, sobretudo em um continente fortemente misturado - com toda a potencialidade que isso implica - em etnias, línguas, religiões, cosmovisões.

Em contrapartida, essa diversidade está fortemente vinculada ao problema das migrações, dos refugiados e das populações em situação de vulnerabilidade; à injustiça e à pobreza. Violência, desintegração familiar, desestruturação do tecido social são hoje elementos presentes como marcas profundas da cultura.

Respeito deverá significar, para a sociedade, responsabilizar-se pela multiplicidade complexa e contraditória que a constitui e elaborar fortes políticas para potencializar essa diversidade.

\section{Incorporar elementos tecnológicos ou transformar a cultura}

É fundamental incorporar as tecnologias de informação e comunicação (TICs), como apropriação de ferramentas imprescindíveis, como garantia ao direito de sua utilização, mas tendo presente que não elas têm valor positivo em si mesmas, superando, além disso, o perigo de uma educação a distância de baixa qualidade destinada ás maiorias, enquanto se reserva a presencial de excelência para grupos minoritários.

Mas urge também reconhecer o profundo impacto que tem na cultura a revolução tecnológica, em particular nos grupos de jovens e adultos. Os processos de espetaculosidade da política, o apagamento da 
distância entre o privado, o público e o comum, entre o natural e o artificial em uma nova estética - para citar apenas alguns aspectos ligados fortemente ao consumo como espaço de constituição de identidade - são, sem dúvida, sinais das profundas transformações na cultura ligadas ao modelo do sucesso individual, da competição e do mercado.

As democracias recuperadas enfrentam desafios desconhecidos diante dessas enormes modificações sociais possibilitadas pelos avanços tecnológicos, que obrigam a educação de adultos a repensar sua contribuição na construção de cidadanias e em novas formas de participação.

\section{Repartir conhecimento ou construir o comum}

No marco das carências educativas - ou escolares - de grande número de populações pertencentes a grupos portadores de múltiplas culturas, e no contexto de sociedades midiáticas, a lógica da repartição dos bens culturais não é suficiente.

Trata-se então de construir a convergência de olhares sobre o estado da situação, para que seja ela que construa o espaço comum capaz de abrigar a multiplicidade.

Um espaço público no qual a totalidade social é posta em cena se constrói com o aporte das especificidades de cada grupo, mas é diferente de cada uma de suas partes. Entretanto, cada subgrupo do conjunto aporta sua singularidade, mas também constrói distância dessa totalidade (Badiou, 1988).

A lógica dialógica que Freire introduz no campo da pedagogia permite pensar a criação constante de uma inovação com o aporte original de cada singularidade. Isso não desaparece com os conflitos de interesses, nem com as contradições, nem com as diferentes perspectivas culturais dos diversos grupos sociais; entretanto, o que ela busca é que sejam resolvidos em termos justos; uma construção dialógica - entendendose por diálogo uma lógica de criação de conhecimentos a partir da convergência de múltiplos olhares sobre a situação e um vínculo em cujo desenvolvimento os sujeitos se constituem.
O comum assim construído forma-se como uma inovação criada a partir do aporte das singularidades do social e oferece superfície para a construção de um laço social, tornando possível a convivência do que é múltiplo, organizando totalidades abertas à sua contínua transformação, com a inclusão das particularidades que fazem a distância dessa totalidade que os alberga e da qual também são produtores. ${ }^{3}$

\section{Fora da escola ou por sua transformação}

A crítica impiedosa aos sistemas escolares dos anos de 1960 transformou-se em defesa e transformação da escola pública nos anos de 1990, paralelamente à mutação do sonho revolucionário em pesadelo neoliberal. Assim, por exemplo, "qualidade” passou a significar "rendimento", "avaliação", "medição" e "participação” na sustentação do edifício escolar por parte das famílias.

O reconhecimento do espaço não-formal como educativo foi, sem dúvida, um avanço democrático em meados do século XX, reconhecendo o valor pedagógico e cultural inscrito em múltiplos espaços sociais, mas tampouco escapou da máquina devoradora de significados.

Atualmente, os processos educativos não escolares têm alto valor democratizador em muitos sentidos, enorme capacidade de dar conta das necessidades sentidas por grandes grupos - em muitos casos invisibilizados - de trabalhar em um terreno geográfico e simbólico ao qual a escola não chega e contribuir de modo significativo para melhorar a qualidade de vida das pessoas envolvidas.

Mas o novo contexto exige que se tomem algumas cautelas. Esses processos são utilizados também para

${ }^{3}$ Esse tema foi desenvolvido na apresentação da autora, Nuevas problemáticas del campo de las alternativas: la construcción de lo común. Reflexiones desde la historia reciente de la educación argentina, no II Encontro Internacional Giros Teóricos. Diálogos e debates. Cidade do México, Faculdade de Filosofia e Letras, UNAM, 20-22 fev. 2008. 
legitimar práticas educativas de baixa qualidade, uso de mão de obra barata; enfim, também podem se tornar uma oferta destinada a grandes grupos, enquanto se reserva para uma minoria o acesso ao sistema e aos graus escolares mais altos.

Por isso, o não-formal não é em si mesmo uma garantia de democracia, sobretudo em um continente onde amplos grupos sociais aspiram acessar estudos formais e chegar à universidade.

Em contrapartida, na América Latina a escola tem sido "bancária" mas também a grande alfabetizadora (Rivero, 2007) e a formadora de gerações de intelectuais capazes de criticá-la; além da enorme quantidade de experiências democratizadoras no interior dos sistemas escolares, em sua longa história.

Porém é importante assinalar que as experiências fora da escola têm acumulado uma riqueza potencialmente disponível; é imprescindível que o sistema a aproveite para sua transformação.

Trata-se de articular, potencializar e não dicotomizar.

\section{Trabalho territorial ou fragmentação}

Um dos elementos que caracterizam o cenário do novo milênio é a crescente visibilidade dos processos micro e das lutas específicas. A caracterização do processo como globalização oculta a "crise estrutural" (Alba Cevallos, 2007) que tem, entre outros elementos, a radicalização dos particularismos e o surgimento de novos atores coletivos não contidos nos partidos políticos tradicionais.

A proliferação de processos de diferentes tipos no âmbito territorial - no amplo espaço do denominado "nãoformal”, mas também por parte de educadores do sistema escolar - tem produzido enorme riqueza pedagógica, política, cultural e a acumulação de conhecimentos, de educadores formados, de materiais produzidos ou preservados e infraestrutura construída. Para atualizar-se, essa potencialidade precisa superar o nível de microexperiência, articulando-se a processos macro, sem perder especificidade nem autonomia, mas integrando o que é comum e enriquecendo-o com sua multiplicidade.
A democracia local não contribui para a justiça quando potencializa a fragmentação.

A dispersão permanente, com a perda de riqueza, energia, acumulação, só se pode contrapor à construção de articulações políticas no marco de projetos que sejam capazes de conter um conjunto diverso.

\section{Autonomia ou privatização}

A relação entre Estado e sociedade civil no aspecto educativo, e em particular na educação de adultos, tem uma longa tradição, na qual - desde pelo menos o século XX - o desempenho de diversos atores, como sindicatos, associações de bairro, partidos políticos, organizações não-governamentais etc., tem cumprido papel fortemente democratizador e inclusivo, sendo, em muitos casos, o principal promotor de ações destinadas a jovens, adultos e grupos subalternos em geral. É fundamental o reconhecimento da imensa quantidade de experiências desenvolvidas por múltiplos atores sociais de altíssimo valor político e pedagógico.

No entanto, “sociedade civil” é também um conceito excessivamente amplo, que engloba um número heterogêneo de atores sociais, dos quais nem todos têm como objetivo principal sua participação no bem comum.

Também engloba a participação de organizações que têm como finalidade apenas o lucro individual, nas quais desaparece a perspectiva de construção de sociedade. O princípio de autonomia liga-se rapidamente à desresponsabilização do Estado. E esse histórico clamor democrático pela escola transforma-se, com enorme facilidade, em “privatização” do espaço público.

Em 2009, o Fórum de Belém, dando continuidade a outros anteriores que construíram um antagonismo aos governos neoliberais na região, contou com a presença dos presidentes de quatro países latinoamericanos. No entanto, eles não conseguirão realizar transformações profundas a não ser com forte apoio das sociedades (Sader, 2009). O desafio que se apresenta para as organizações populares é construir um vínculo com o Estado que as potencialize em suas enormes possibilidades democratizadoras. 


\section{Formação de mão de obra ou saberes socialmente produtivos}

"Formação para o trabalho" é outro enunciado que, com a aparência de um reclamo democratizador, pode ser construído como uma proposta que oculta as lógicas econômicas estruturantes dos problemas de desemprego e falta de trabalho e relega a um plano individual uma questão de ordem estrutural. Fala-se então de empregabilidade, certificação de competências, subsistência.

Oferece-se a uma população sofrida a ilusão de uma melhoria em sua qualidade de vida pela aquisição de certos conhecimentos e/ou certificações, discurso que também esconde aquilo que oferece na realidade: inclusão subordinada, compensada com a possibilidade ou a fantasia de acesso a certos níveis de consumo. A ambição do trabalhador é apropriada pelo capital.

Mas a formação para o trabalho pode ser também profundamente democrática se for capaz de transformar os saberes do trabalho em saberes socialmente produtivos (Puiggrós, 2003), subordinando a lógica do mundo da economia à de formação de sociedade. O trabalho recupera, assim, sua produtividade para a consolidação de identidades e a construção de vínculos e múltiplas formas de organização social e se orienta no marco de políticas integradas e de cuidado com o meio ambiente.

Nesse marco, o reconhecimento de saberes adquiridos ao longo da vida e vinculados às certificações do sistema escolar tem alto valor reparatório em termos do comum de cidadania, por oposição ao uso que se faz da chamada "certificação de competências", quando é útil apenas para a construção de um circuito de mão de obra a serviço do empresariado e não de um processo de desenvolvimento.

\section{Coordenar ações ou articular políticas}

A coordenação de ações entre diversos fatores e em diferentes níveis da estrutura do Estado e da sociedade é fundamental na educação de adultos - e é assim reconhecida há vários anos. Mas não é demais simplesmente assinalar que não se trata de um problema meramente "técnico", mas que também requer a elaboração de acordos políticos que orientem no sentido de uma direcionalidade, e isso não se resolve senão em termos de criação de âmbitos de processamento de conflitos e diferenças.

Uma educação no marco de um projeto transformador implica hegemonia, condução política, traçado de horizontes, perspectiva. Enfim, a articulação implica política e, nesse contexto, a coordenação de ações é possível.

\section{Pesquisa e sistematização de experiências}

O incremento da pesquisa em educação de adultos, embora conte com alguns apoios importantes na região, necessita mais forma e desenvolvimento nas linhas de sistematização e também daquilo que se pode chamar de pesquisa no sentido tradicional.

A sistematização de experiências é uma fonte inesgotável de produção de conhecimentos quando não se converte em um relato de fatos e situações, mas potencializa sua capacidade de produzir pensamento capaz de ser acumulado, comunicado, debatido. Do mesmo modo, a pesquisa básica é fundamental quando não perde a perspectiva das problemáticas surgidas do trabalho em terreno concreto.

O grande aporte de Freire foi possível porque ele articulou suas práticas com uma profunda reflexão político-teórica (Beisiegel, s.d.).

\section{Avaliação como melhoria}

A avaliação que aparece com força é, sem dúvida, uma ferramenta imprescindível. No entanto, não garante em si mesma nem eficácia nem eficiência. Obter o estado da situação não a melhora nem a modifica em si mesma.

Nesse sentido é necessário precisar os elementos do processo avaliativo adequados a cada momento e objeto. Avaliar implica discutir o que, como, para quê, políticas, experiências, processos, dimensões 
materiais, cognitivas, sociais; definir objetivos, metodologias, custos, momentos etc.

Enfim, o que se requer é uma política de avaliação que, evidentemente, não a reduza ao "rendimento" nem à produção de relatórios de alto custo que não são aproveitados para a melhoria do processo.

\section{Alfabetização como termo autopositivo}

Dizia um artigo de jornal há alguns anos:

O despejo de Ramonita Bustamante ocorrido em 2003 converteu-se em um caso paradigmático da expulsão de suas terras dos camponeses cordoveses. Na imprensa esse despejo foi relacionado com a situação de analfabetismo da senhora e de seus familiares. Tal como foi apresentado, o problema é a educação; a pobreza e o despejo são resultado da "ignorância" daqueles que nunca foram à escola nem se alfabetizaram. (Cragnolino, 2007)

A jornalista do citado artigo também diz que a desalojada Ramonita não estudou por "pautas culturais”, por "falta de motivação por causa da resignação, às vezes ancestral, desses habitantes”.

Esse relato é um dos muitos exemplos que evidenciam que não apenas subsiste um olhar que culpa o analfabeto por sua própria carência escolar - por ter "desertado" - mas vem a propósito para ocultar situações estruturais de injustiça, que pouco têm a ver com a escolaridade alcançada.

A outra face desse mesmo enunciado é o uso da alfabetização como "autopositivo”, esquecendo a importância do contexto no qual ela se desenvolve, as possibilidades de continuidade para não perder as conquistas alcançadas, enfim, as complexidades de desenvolvimento de um processo que não necessariamente é vivido pelos destinatários com a mesma urgência com que são apresentados nos documentos oficiais e acadêmicos.

Por isso, é importante então ressaltar que a educação de adultos não será conseguida senão no marco de transformações "estruturais e sem a convergência de outras políticas” (Torres, 2008).

\section{Em síntese}

A América Latina manifesta novamente que tem (como cada uma das regiões) algo original para aportar no campo geral da modalidade. Heterogênea em geografias, línguas, etnias, culturas, situações socioeconômicas, tem construído ao longo de sua longa história uma identidade complexa, contraditória, conflituosa. Ser a região menos equitativa do mundo é algo que ganhamos à força dos processos político-culturais de longo e médio prazo também compartilhados e constituídos na matriz da traumática incorporação do continente ao cenário moderno na particular forma de situação colonial. ${ }^{4}$

As democracias recuperadas desde as últimas décadas do século passado abrem o espaço público onde é possível a dissensão e a criação; nas quais o conflito - inevitável, pois os interesses são diversos e contraditórios; os projetos e os atores sociais são múltiplos - encontra formas não traumáticas de processamento e a possibilidade de subordinar sua resolução a um horizonte de justiça social.

A América Latina enfrenta hoje diversas possibilidades de futuro. Recupera, assim, a possibilidade de uma narrativa que ofereça superfícies para a inscrição de diversas possibilidades de projeto social e biográfico, sem o que não é possível educar, não tem sentido ensinar nem surge o desejo de aprender.

Não é possível definir a problemática da educação de adultos fora de uma perspectiva não pensada no marco de uma história inercial de tendências presentes, mas sim desde uma perspectiva que assuma a primazia dos sujeitos na construção da história, atravessada pelo conflito e pela contingência.

É nesse marco que é possível imaginar políticas em que a educação de adultos seja uma parte substantiva de políticas de desenvolvimento e consolidação democrática, aportando o enorme caudal acumulado com respeito ao vínculo entre educação e transformação.

\footnotetext{
${ }^{4}$ Ver, entre outros: Mignolo (2000) e Wallerstein (1979).
} 
Nesse sentido, também há uma apropriação de categorias da educação popular por múltiplos discursos de diferentes matizes políticos que merece ser desconstruída. Cabe ainda assinalar a centralidade do aspecto educativo como dimensão presente em processos de transformação política e/ou econômica, imprescindíveis para produzir o espaço de geração de conhecimentos diante de situações inéditas.

Políticas fortes de apoio à educação de adultos podem contribuir para a formação de gerações capazes de assumir as rédeas de novos projetos sociais. Por isso, articular políticas de diversos setores e múltiplos atores não é um problema administrativo; implica situar o horizonte que as orienta; é uma decisão de política democrática que é necessário exigir sem minimizar o problema que apresenta em termos de construção de hegemonia.

Do mesmo modo, a cooperação internacional tem força quando se articulam projetos macrocoordenados a partir do Estado democrático, a partir do qual se articulam dissensos políticos.

Uma prospectiva nada mais é que uma aposta política e, portanto, não é linear, segura nem tranquila.

Enfim, alcançar a igualdade social, econômica, política, requer reconhecer que a igualdade (Rancière, 2003) é fundamento daquela base da possibilidade do diálogo freireano. Não se trata de fazer do outro um igual, mas sim reconhecê-lo como tal. Não para o futuro, mas sim para as possibilidades inscritas no presente.

Abre-se, assim, uma gama de possibilidades cujos pontos extremos podem ser expostos em termos um pouco dicotômicos em benefício da clareza: assumir um horizonte de justiça e dívida interna como condição e impulso do desenvolvimento, o que leva a um progressivo aprofundamento das transformações; ou políticas de melhoramento que permitam a continuidade das lógicas de subalternidade política, econômica e social de amplos setores sociais.

A democracia abre o espaço do direito de todos a contribuir para o que é comum, desde que essa política tenha como horizonte a justiça. As riquezas intangíveis do povo estão disponíveis; faz-se um cálculo estreito ou uma aposta forte e generosa no futuro: uma conta ou uma política. Se não há projeto (que não é tal se não for socialmente construído) será a ganância que dirá o que fazer (Badiou, 2005).

\section{Referências bibliográficas}

ALBA CEVALLOS, Alicia de. Currículum-sociedad. El peso de la incertidumbre, la fuerza de la imaginación. México: Editorial ISSUE/Plaza y Valdés, 2007.

BADIOU, Alan. El ser y el acontecimiento. Buenos Aires: Manantial, 1988.

Le siècle. Paris: Seuil, 2005.

BEISIEGEL, Celso de Rui. Observaciones sobre la teoría y la práctica en Paulo Freire. s.d. Disponível em: <http://www. hottopos.com/mirand7/observaciones_sobre_la_teoria_y_htm $>$. Acesso em: jul. 2003.

CRAGNOLINO, Elisa. El analfabetismo de los campesinos del norte cordobés. Una mirada histórica y social. In: CONGRESO IBEROAMERICANO DE HISTORIA DE LA EDUCACIÓN LATINOAMERICANA - Contactos, cruces y luchas en la historia de la educación latinoamericana, 8., Buenos Aires, 2007. Anais... Buenos Aires: La Sociedad Argentina de Historia de la Educación, 2007.

FREIRE, Paulo. Pedagogía del oprimido siglo veintiuno. Buenos Aires: Tierra Nueva, 1975.

LACLAU, Ernesto. Nuevas reflexiones sobre la revolución en nuestro tiempo. Buenos Aires: Nueva Visión, 1993.

. Emancipación y diferencia. Buenos Aires: Ariel, 1996.

MIGNOLO, Walter D. La colonialidad a lo largo y a lo ancho: el hemisferio occidental en el horizonte colonial de la modernidad. In: LANDER, Edgardo (Comp.). La colonialidad del saber: eurocentrismo y ciencias sociales. Perspectivas latinoamericanas. Buenos Aires: CLACSO, 2000.

PUIGGRÓS. Adriana. El lugar del saber. Buenos Aires: Galerna, 2003.

RANCIÈRE, Jacques. El maestro ignorante; cinco lecciones sobre la emancipación intelectual. Barcelona: Laertes, 2003.

RIVERO, José. Bases para una alfabetización integral en América Latina. In: REUNIÓN COMISIÓN DE EXPERTOS IBEROAMERICANOS - Alfabetización y Educación básica de las Personas Jóvenes y Adultas, 8., Cartagena de Índias/Bogotá, 2007. Anais... Cartagena de Índias/Bogotá: s.ed., 2007. 
SADER, Emir. Presidentes latinoamericanos en el Foro Social Mundial. Info Novidades Fórum Latino-americano de Políticas Educativas - FLAPE, n. 71, 2 fev. 2009.

TODOROV, Tzvetan. La peur des barbares. Paris: Laffont, 2008. TORRES, Rosa Maria. Un problema de nomenclatura e identidad de la educación de jóvenes y adultos. s.d. Disponível em: <http:// confinteavi.blogspot.com/>. Acesso em: 2009.

Compromisso renovado para a aprendizagem ao longo de toda a vida. Proposta da Região da América Latina e do Caribe. VI CONFINTEA. 2008.

UNESCO/IUAL/INEA. Conferencia Regional da América Latina e do Caribe sobre Alfabetização e Preparatória para VI CONFINTEA. De la alfabetización al aprendizaje a lo largo de toda la vida: Hacia los desafíos del siglo XXI. Cidade do México, 10-13 set. 2008.

WALLERSTEIN, Immanuel. El moderno sistema mundial. La agricultura capitalista y los orígenes de la economía-mundo europea en el siglo XVI. Madrid: Siglo XXI Editores, 1979.
LIDIA MERCEDES RODRIGUEZ, doutora em filosofia pela Universidade de Paris VIII, é professora na Faculdade de Filosofía e Letras da Universidade de Buenos Aires e no Programa Alternativas Pedagógicas e Prospectiva Educativa para América Latina, assim como na Universidade Nacional de Entre Rios. Publicações recentes: Escolarización de jóvenes y adultos (Informe del Ministerio de Educación, Ciencia y Tecnología de la Nación, 2005); Paulo Freire: frontera de la pedagogía moderna latinoamericana (Revista Anuario de Historia de la Educación, v. 5, n. 5, p. 177-202, 2004); Escuela de pobres o pedagogía del oprimido (In: CONGRESO INTERNACIONAL DE EDUCACIÓN - La Formación docente. Evaluaciones y nuevas prácticas en el debate educativo contemporáneo, 2., Santa Fé, 2004. Anais... Santa Fé: Universidad Nacional del Litoral, 2004).E-mail : lidiame@fibertel. com.ar, lidiamero@gmail.com.ar

Recebido em março de 2009 Aprovado em abril de 2009 
of $18^{\text {th }}$ century European liberalism: Mandeville's liberalism, which fears the people's instruction; Smith's liberalism, which requires a minimal instruction (reading, writing and counting) for all workers; and Condorcet's liberalism, which advocates a common, universal, public, free and mandatory education. Based on the principle of the equality of all human beings, Condorcet opposes Mandeville and goes beyond Smith, as the latter base their positions only on the principle of freedom. The choice starts from the assumption that the confrontation that was established between them might be a benchmark to understand the kind of liberalism that prevailed in the Brazilian Empire, particularly at the time of the electoral reform (the so-called Saraiva Act of 1881) that introduced direct elections and eventually excluded the illiterate from the right to vote. But they could also serve as a benchmark to understand what occurs in Brazil today.

Key words: liberalism; Brazil; literacy; schooling.

Liberalismos y educación, o por qué Brasil no podía ir más allá de Mandeville

Este trabajo examina a tres autores que expresan versiones típicas del liberalismo europeo del siglo XVIII: el liberalismo de Mandeville, que teme a la instrucción del pueblo; el liberalismo de Smith, el cual requiere una instrucción mínima (leer, escribir y contar) para todos los trabajadores; y el liberalismo de Condorcet, que defiende una educación común, universal, pública, gratuita y obligatoria. Fundamentado en el principio de la igualdad de todos los seres humanos, Condorcet se contrapone a Mandeville y avanza para más allá de Smith, que fundamentan sus posiciones apenas en el principio de la libertad. La opción se apoyó en la suposición de que el confronto establecido entre ellos podría constituirse en referencia para el entendimiento del tipo de liberalismo que prosperó en Brasil Imperio, en especial en el momento de la reforma electoral de 1881, la cual, al introducir la elección directa, determinó la exclusión de los analfabetos del derecho de voto, mas es referencia también para el entendimiento de lo que pasa hoy en el País.

Palabras claves: liberalismo; Brasil; alfabetización; escolarización.

Lidia Mercedes Rodriguez

Educação de jovens e adultos na América Latina: políticas de melhoria ou de transformação; reflexões com vistas à VI CONFINTEA

Ainda não se consolidou uma proposta alternativa para incorporar as grandes massas aos processos educativos. Não obstante, os processos de abertura política que se verificam na América Latina nos últimos anos abrem espaço para a formulação de novos paradigmas. A disjuntiva é ceder às propostas liberalizantes da globalização, consolidando a educação como mercadoria, ou retomar o conceito freireano de educação, com vista a contribuir para a construção da cidadania e da participação. O desafio para a CONFINTEA VI é construir sínteses capazes de levar a consensos sobre conteúdos e métodos de educação de jovens e adultos, além de atender às urgências, encarando a educação não como custo ou investimento, mas como direito ou serviço, e promover a construção de espaços públicos nos quais se edifique a totalidade social com a especificidade de cada grupo, no contexto do multiculturalismo.

Palavras-chave: educação de jovens e adultos; novos paradigmas; multiculturalismo.
Adult and youth education in Latin America: policies of improvement or transformation; reflections with a view to CONFINTEA VI

Until now no alternative proposal for incorporating the masses into educational processes has been consolidated. However, the processes of political democratization which have been seen in Latin America in recent years have opened space for the elaboration of new paradigms. The disjunctive is either to give in to liberalizing proposals of globalization, consolidating education as a commodity, or to return to the Freirian concept of education with a view to contributing to the construction of citizenship and participation. The challenge for CONFINTEA VI is to construct syntheses capable of achieving consensus on contents and methods for adult and youth education in addition to attending to the urgencies, understanding education not as a cost or investment but as a right or service, and to promote the construction of public spaces in which the social totality is built on the specificity of each group in the context of multiculturalism.

Key words: adult and youth education; new paradigms; multiculturalism.

\section{Educación de adultos en América} Latina: políticas de mejora o de transformación; reflexiones en vistas a la CONFINTEA VI

Todavía no se ha consolidado una propuesta alternativa para incorporar a las grandes masas en los procesos educativos. Sin embargo, los procesos de apertura política que se están desarrollando en América Latina en los últimos años abren espacio para la formulación de nuevos paradigmas. La disyuntiva es ceder a las propuestas liberalizantes de la globalización, consolidando la educación como mercancía, o retomar el concepto 
freireano de educación, visando contribuir para la construcción de la ciudadanía y la participación. El desafío para la CONFINTEA VI es construir síntesis capaces de llevar a consensos sobre contenidos y métodos de educación de jóvenes y adultos, además de atender a las urgencias, mirando la educación no como costo o inversión, sino como derecho y servicio, y promover la construcción de espacios públicos en los que se erija la totalidad social con la especificidad de cada grupos, en el contexto del multiculturalismo.

Palabras claves: educación de jóvenes y adultos; nuevos paradigmas; multiculturalismo.

John Aitchison

\section{A voz do Sul na CONFINTEA VI: a} agenda da África

O texto é uma síntese da agenda africana para a CONFINTEA VI, preparada a partir de relatórios nacionais trazidos pelos 46 países africanos reunidos em Nairóbi, Quênia, em novembro de 2008. Depois de breve descrição de um contexto desencorajador, o autor elenca as questões que foram consideradas prioritárias quanto à estrutura, gestão, financiamento e qualidade da educação de adultos na África. Diante da constatação de que os problemas da área são massivos, abrangentes e sistêmicos, os representantes reunidos em Nairóbi sugeriram maior intercâmbio entre países e a formação de um grupo de alto nível, multissetorial, que levantasse fundos para o financiamento da educação de adultos na África. Além disso, recomendaram que a CONFIN-

TEA VI tivesse uma orientação voltada para resultados e para ação e que fosse estabelecido um sistema efetivo de acompanhamento da implementação das deliberações tomadas.

Palavras-chave: educação de adultos na África; CONFINTEA VI.
The South speaking to CONFINTEA VI: the African agenda

The text is a synthesis of the African agenda for CONFINTEA VI based on national reports prepared by 46 African countries present in Nairobi, Kenya, in November 2008. After a brief description of the discouraging context, the author lists the questions which were considered priority with regard to structure, management, financing and quality of adult education in Africa. Faced with the affirmation that the problems of the area are massive, wide-ranging and systemic, the representatives present in Nairobi suggested greater exchange between countries and the creation of a multi-sectoral high level group to raise funds for the financing of adult learning and education in Africa. In addition, they recommended that CONFINTEA VI should be oriented towards results and action and that an effective system for monitoring the implementation of the deliberations taken should be established.

Key words: adult education in Africa; CONFINTEA VI.

\section{La voz del Sur en la CONFINTEA} VI: la agenda de África

El texto es una síntesis de la agenda africana para la CONFINTEA VI, preparada a partir de informes nacionales traídos por los 46 países africanos reunidos en Nairobi, Kenia, en noviembre de 2008. Después de de una breve descripción de un contexto desencorajador, el autor numera las cuestiones que fueron consideradas prioritarias en cuanto a la estructura, gestión, financiamiento y calidad de la educación de adultos en África. Delante de la constatación de que los problemas del área son masivos, abrangentes y sistémicos, los representantes reunidos en Nairobi sugirieron un mayor intercambio entre países y la formación de un grupo de alto nivel, multisectorial, que levantara fondos para el financiamiento de la educación de adultos en África. Además de esto, recomendaron que la CONFINTEA VI tuviera una orientación apuntada para resultados y para acción, y que fuera establecido un sistema efectivo de acompañamiento de la implementación de las deliberaciones tomadas.

Palabras claves: educación de adultos en África; CONFINTEA VI.

Heribert Hinzen

Educação de adultos

ao longo da vida: desenvolvimentos atuais e interdependentes na Alemanha e na Europa, a caminho da VI CONFINTEA

A educação e a aprendizagem de adultos têm recebido mais atenção e reconhecimento a partir do conceito de aprendizagem ao longo da vida, que se torna agora o principal paradigma para a teoria e a prática educacionais. Este movimento se acentua no contexto de organismos como a UNESCO, a União Europeia e a Associação Alemã de Educação de Adultos (DVV), no caso da Alemanha. Há claras indicações de que cada um desses organismos exerce mútua influência sobre os outros, por meio das políticas, programas, modelos e até mesmo pela administração de recursos financeiros. Isto é exemplificado no artigo pela indicação de processos que vêm ganhando importância nos últimos anos, na preparação da VI Conferência Mundial de Educação de Adultos - VI CONFINTEA.

Palavras-chave: educação de adultos na Europa; VI CONFINTEA.

Lifelong Adult

education: current and

interdependent developments in

Germany, Europe and elsewhere, on the road to CONFINTEA VI

Adult learning and education

has received more attention and recognition since the dissemination of the concept of lifelong learning, which 